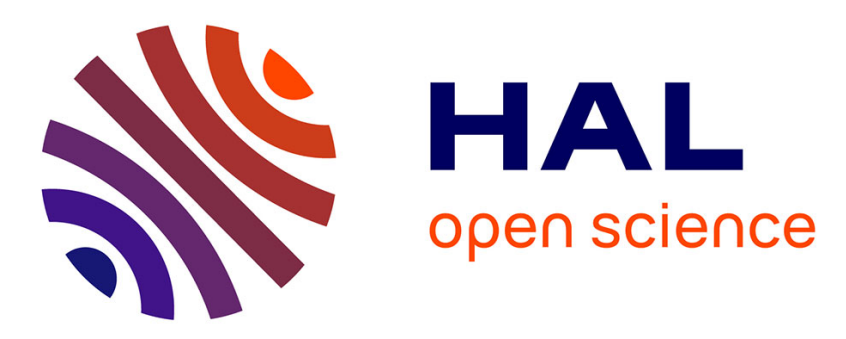

\title{
Evolution of structural and magnetic properties of multifunctional bismuth iron garnets upon $\mathrm{Ca}$ and $\mathrm{Y}$ doping
}

Adrien Teurtrie, Laura Bocher, Alexandra Mougin, Niels Keller, Alexandre Gloter, Elena Popova

\section{To cite this version:}

Adrien Teurtrie, Laura Bocher, Alexandra Mougin, Niels Keller, Alexandre Gloter, et al.. Evolution of structural and magnetic properties of multifunctional bismuth iron garnets upon Ca and $\mathrm{Y}$ doping. Physical Review Materials, 2020, 4 (6), 10.1103/PhysRevMaterials.4.064401 . hal-02992690

\section{HAL Id: hal-02992690 https://hal.science/hal-02992690}

Submitted on 13 Nov 2020

HAL is a multi-disciplinary open access archive for the deposit and dissemination of scientific research documents, whether they are published or not. The documents may come from teaching and research institutions in France or abroad, or from public or private research centers.
L'archive ouverte pluridisciplinaire HAL, est destinée au dépôt et à la diffusion de documents scientifiques de niveau recherche, publiés ou non, émanant des établissements d'enseignement et de recherche français ou étrangers, des laboratoires publics ou privés. 


\title{
Evolution of structural and magnetic properties of multifunctional bismuth iron garnets upon Ca and Y doping
}

\author{
Adrien Teurtrie $\odot,{ }^{1,2}$ Laura Bocher $\odot,{ }^{1}$ Alexandra Mougin $\odot,{ }^{1}$ Niels Keller, ${ }^{2}$ Alexandre Gloter $\odot,{ }^{1, *}$ and Elena Popova ${ }^{2}{ }^{2, \dagger}$ \\ ${ }^{1}$ Université Paris-Saclay, CNRS UMR 8502, Laboratoire de Physique des Solides (LPS), 91405 Orsay, France \\ ${ }^{2}$ Groupe d'Etude de la Matière Condensée (GEMaC), Université de Versailles Saint Quentin en Yvelines - CNRS, \\ Université Paris-Saclay, 78035 Versailles Cedex, France
}

(Received 18 March 2020; accepted 29 April 2020; published 1 June 2020)

\begin{abstract}
A multiscale approach is reported to understand the influence of the $\mathrm{Ca}$ and $\mathrm{Y}$ co-substitution in Bi-rich iron garnet thin films. Recently, it has been demonstrated that site-selective co-substitution of $\mathrm{Ca}^{2+}$ and $\mathrm{Y}^{3+}$ in bismuth iron garnet (BIG) leads to either $n$ - or $p$-type semiconductor behavior. However, the evolution of the structural and magnetic properties of bismuth iron garnet upon doping is still unknown. In the (Ca,Y):BIG, thin films grown by pulsed laser deposition onto $\mathrm{Gd}_{3} \mathrm{Ga}_{5} \mathrm{O}_{12}$ substrates, structural investigations confirm the epitaxial growth of doped thin films with high crystallinity and a complete strain relaxation from $20 \mathrm{~nm}$ above the film/substrate interface. While x-ray diffraction only evidences a single-phase garnet, the presence of secondary phase nanocrystallites, that are absent in pure BIG grown in similar conditions, is observed by aberration-corrected scanning transmission electron microscopy. These nanocrystallites form in between garnet grains as textured and poorly crystallized hematite. Despite the presence of nanoneedles, Ca and Y co-substitution preserves the giant Faraday rotation of pure BIG and maintains the Curie temperature above $590 \mathrm{~K}$. Only minor energy shifts $(80 \mathrm{meV})$ or small intensity changes $(10 \%)$ of the Faraday rotation are observed upon doping or annealing and are mainly related to band-gap evolution and cell volume change. Furthermore, the easy magnetization axis rotates towards in the out-of-plane direction upon doping which is also promising for potential applications in spintronics.
\end{abstract}

DOI: 10.1103/PhysRevMaterials.4.064401

\section{INTRODUCTION}

Ternary oxide thin films and their doped counterparts present a wide range of functional properties. However, due to the presence of two or more cations, the growth of such films is often a challenging task. It especially concerns the control of the stoichiometry and homogeneity of the cation distribution in the films [1]. The phase diagram is often complexified upon doping and various secondary phases may be favoured to the detriment of the material properties.

Bismuth iron garnet $\left(\mathrm{BIG}, \mathrm{Bi}_{3} \mathrm{Fe}_{5} \mathrm{O}_{12}\right)$ is one of the remarkable ternary functional oxide in particular for its magneto-optical properties. Pure BIG possesses, among other properties, a giant Faraday rotation $\left(\theta_{F}\right)$ of $-17^{\circ} \mu \mathrm{m}^{-1}$ at $580 \mathrm{~nm}$ [2] and a significant magneto-electrical coupling [3]. BIG films can mostly be synthesized by out-of-equilibrium techniques such as pulsed laser deposition (PLD). While the possibility to grow single-phase BIG by PLD with high structural quality [4] has already been shown, the co-doping of this material might induce a structural disorder that would alter its properties. It is a topic of current interest, as the co-doping of BIG was recently used to develop an additional functionality in this material. Co-substitution of $\mathrm{Ca}$ and $\mathrm{Y}$ aims at developing a magnetic semiconductor based on BIG.

\footnotetext{
*Corresponding author: alexandre.gloter@u-psud.fr

†Corresponding author: olena.popova@uvsq.fr
}

$\mathrm{Ca}$ is expected to induce spin-polarized $p$-type conduction. A complementary concentration of $\mathrm{Y}$ is supposed to maintain 2.5 $\mathrm{Bi}$ per f.u. to preserve the magnetic properties of BIG. Ca and $\mathrm{Y}$ co-substituted $\mathrm{BIG}, \mathrm{Bi}_{2.5} \mathrm{Ca}_{x} \mathrm{Y}_{0.5-x} \mathrm{Fe}_{5} \mathrm{O}_{12}$ (hereafter $\left.\mathrm{B}\left(\mathrm{Ca}_{x} \mathrm{Y}_{0.5-x}\right) \mathrm{IG}\right)$ thin films with $\mathrm{x}=\{0.0 ; 0.1 ; 0.2 ; 0.3\}$ grown onto $\mathrm{Gd}_{3} \mathrm{Ga}_{5} \mathrm{O}_{12}$ (GGG) (001) substrates have shown an electrical conductivity increase of at least eight orders of magnitude compared to yttrium iron garnet (YIG) [5]. Indeed, it was determined that the resistivity can be modified by either $\mathrm{Ca}$ doping or by the presence of oxygen vacancies in $\mathrm{B}\left(\mathrm{Ca}_{0.0} \mathrm{Y}_{0.5}\right) \mathrm{IG}$ films. Furthermore, interfacial and doping effects are known to possibly lead to interesting magnetic anisotropy mechanisms in such transition metal oxide thin films [6-8].

To further understand the influence of the doping on the magnetic properties of the $\mathrm{B}\left(\mathrm{Ca}_{x} \mathrm{Y}_{0.5-x}\right) \mathrm{IG}$ thin films, we combine macroscopic and microscopic scale investigations. Indeed, such a study of Bi-rich iron garnets was still lacking and could allow to fine tune their physical properties. In this paper, we first focus on the investigation of the structural and microstructural properties using both x-ray diffraction and electron microscopy techniques. The strain relaxation and the occurrence of secondary phases are thus investigated down to the nanometer scale. Secondly, the magneto-optical and magnetic properties of these doped $\mathrm{B}\left(\mathrm{Ca}_{x} \mathrm{Y}_{0.5-x}\right) \mathrm{IG}$ films as a function of the concentration of the dopants were measured using by Faraday spectroscopy and Kerr rotation and discussed with respect to state-of-the-art undoped BIG. 


\section{EXPERIMENTAL DETAILS}

$\mathrm{Bi}_{2.5} \mathrm{Ca}_{x} \mathrm{Y}_{0.5-x} \mathrm{Fe}_{5} \mathrm{O}_{12}(x=0.0,0.1,0.2$, and 0.3) thin films with thicknesses ranging from 150 to $210 \mathrm{~nm}$ were grown by PLD on GGG (001) substrates. The BIG targets substituted with $\mathrm{Ca}$ and $\mathrm{Y}$ have been prepared from high purity powders (99.99\% for Ca precursors and $99.999 \%$ for all other precursors) using a standard ceramic processing method. An excimer $\mathrm{KrF}$ laser with a wavelength of $248 \mathrm{~nm}$ and pulse duration of $20 \mathrm{~ns}$ was used for the film deposition. The laser fluency and frequency were maintained at about $1.2 \times 10^{-4} \mathrm{~J} \mathrm{~m}^{-2}$ and $2 \mathrm{~Hz}$ respectively for all the samples of the series. The samples were grown at $1050 \mathrm{~K}$ (nominal temperature at the backside of the heater) in a stable oxygen pressure of $0.7 \mathrm{~Pa}$. After the growth, the sample is cooled down in the growth atmosphere at an average rate of $5 \mathrm{~K} \mathrm{~min}^{-1}$. The films were annealed ex situ (post-annealing hereafter) at $870 \mathrm{~K}$ in an $\mathrm{O}_{2}$ flux of $50 \mathrm{ml} \mathrm{min}^{-1}$ for 48 hours (TA48) or 96 hours (TA96). The long annealing time was chosen to ensure the complete film oxygenation, a much shorter annealing times at a slightly higher temperature would lead to the same results.

The Faraday rotation spectroscopy and Curie temperature measurements were done using a custom designed experimental magneto-optical (MO) setup described in the work of Deb et al. [9]. The applied magnetic field was perpendicular to the film plane (out-of-plane, o-o-p). Faraday rotation spectroscopy measurements were performed at $300 \mathrm{~K}$ with applied field values of $\pm 0.5 \mathrm{~T}$ which was sufficient to reach full magnetic saturation. A very similar optical bench was used to determine the magneto-optical Kerr effect, modified for reflection measurements parallel (in-plane, i-p) or perpendicular (o-o-p) to the film plane [10]. In the Kerr setup, the applied magnetic field was either $\pm 0.4 \mathrm{~T}$ o-o-p or $\pm 0.3 \mathrm{~T}$ i-p and the light source was a He-Ne laser with a wavelength of $633 \mathrm{~nm}$. The Curie temperature $\left(T_{\mathrm{C}}\right)$ was determined from the Faraday rotation at saturation at $550 \mathrm{~nm}$ with the sample mounted in a furnace that can reach $800 \mathrm{~K}$. X-ray diffraction (XRD) was performed on a Seifert four-circle X-ray diffractometer using $\mathrm{Cu} K_{\alpha 1}$ wavelength with an angular resolution of $0.001^{\circ}$.

For electron spectromicroscopy studies, cross-sectional electron transparent samples were prepared by focused ion-beam (FIB) on a SCIOS dual-beam platform (FEIThermofischer). A JEOL $2010 \mathrm{~F}$ operated at $100 \mathrm{kV}$ was used for low-magnification bright-field imaging and selected area electron diffraction (SAED). A Nion UltraSTEM 200 with spherical aberration correction (Cs) was used for atomic resolution dark-field imaging and for electron energy-loss spectroscopy (EELS). The microscope was operated at $100 \mathrm{kV}$ with 30 and 50 mrad of convergence and collection angles, respectively. The probe current was approximately $50 \mathrm{pA}$. The geometric phase analysis (GPA) was performed with the FRWRTOOLS plug in for DIGITALMICROGRAPH [11]. The mask size used was around $1 / 2 \mathrm{a}_{\mathrm{GGG}}\left(0.4 \mathrm{~nm}^{-1}\right)$. A set of two identical images oriented at $90^{\circ}$ to each other was systematically acquired with a $4096 \times 4096 \mathrm{px}^{2}$ resolution to extract in-plane and out-of-plane relative strain maps [12] and therefore to investigate the evolution of the local lattice parameters through the film/substrate interface as well as the strain distribution in the doped BIG films.

\section{A. Results and discussion}

As-grown $\mathrm{B}\left(\mathrm{Ca}_{x} \mathrm{Y}_{0.5-x}\right) \mathrm{IG}$ films tend to present oxygen off-stoichiometry [5]. Hence, post-annealings under oxygen flux (TA48 and TA96) were performed to aim for oxygen stoichiometric thin films. Figure 1(a) presents typical $\theta-2 \theta$ x-ray diffraction patterns for as-grown and post-annealed films. All the reflections belong to the garnet phase oriented along [001] with full width at half maximum (FWHM) below $0.15^{\circ}$ in $2 \theta$. These FWHM values are 0.05 to $0.10^{\circ}$ lower than previous values reported in the literature [13-15], indicating that the investigated films have a lower o-o-p mosaicity. Figure 1(b) displays a zoom on the (004) reflection of the as-grown and post-annealed $\mathrm{B}\left(\mathrm{Ca}_{0.0} \mathrm{Y}_{0.5}\right) \mathrm{IG}$ where the presence of Laue oscillations reveal that these films have a coherent crystal structure over the probed volume, i.e., hundreds of $\mathrm{nm}^{3}$. It should be noted that Laue oscillations were only reported for much lower concentrations of $\mathrm{Bi}$, i.e., up to $1.5 \mathrm{Bi}$ per formula unit (f.u.), in Bi-doped YIG systems either grown by PLD [16] or by liquid phase epitaxy [8]. These oscillations are detected for the films without or with a low $\mathrm{Ca}$ concentration, i.e., $x \leqslant 0.1$ per f.u. The absence of Laue oscillations for higher $\mathrm{Ca}$ content indicates a higher structural disorder. After TA48 and TA96, all the films keep the same structural features with an identical crystal symmetry as the as-grown films [Figs. 1(a) and 1 (b) for $\left.\mathrm{B}\left(\mathrm{Ca}_{0.0} \mathrm{Y}_{0.5}\right) \mathrm{IG}\right]$. Contrary to what has been observed for pure BIG films [17], the long annealing times are not detrimental to the doped film quality. The presence of Laue oscillations in combination with the low FWHM confirms the high structural quality of the films based on the XRD results. The epitaxial growth of the films with cube-oncube relation is confirmed by reflection high-energy electron diffraction (not shown here).

All the as-grown co-substituted films possess a slightly larger or equal o-o-p lattice parameter than stoichiometric BIG, i.e., $1.262 \mathrm{~nm}$ [4] [Fig. 1(c)]. A priori, this trend is unexpected since $\mathrm{Bi}^{3+}$ is larger than $\mathrm{Y}^{3+}$ and $\mathrm{Ca}^{2+}\left(\mathrm{r}_{\mathrm{Y}^{3+}}=\right.$ $104 \mathrm{pm}<\mathrm{r}_{\mathrm{Ca}^{2+}}=114 \mathrm{pm}<\mathrm{r}_{\mathrm{Bi}^{3+}}=117 \mathrm{pm}$ ) [18] and $\mathrm{Y}-$ doped BIG was already experimentally reported with a smaller volume [19] assuming a cubic unit cell. Indeed, the in-plane lattice parameter of TA96 $\mathrm{B}\left(\mathrm{Ca}_{0.0} \mathrm{Y}_{0.5}\right) \mathrm{IG}$ was also measured using the $(012)$ reflection $(1.27 \pm 0.2 \mathrm{~nm})$ and it is not significantly different from the out-of-plane lattice parameter. The TA48 films present a decrease of $0.1 \%-0.3 \%$ of their o-o-p lattice parameters compared to their as-grown state indicating the effective filling of the oxygen sublattice. Then, the larger o-o-p lattice parameters of the as-grown films strongly indicate that they are oxygen off-stoichiometric [20]. After TA96, the o-o-p does not significantly decrease within the error margins suggesting that the oxygen sublattice was already completely filled after TA48. For both as-grown and TA48 films, the Ca-doped thin films have a $0.5 \%$ larger o-o-p lattice parameter than $\mathrm{B}\left(\mathrm{Ca}_{0.0} \mathrm{Y}_{0.5}\right) \mathrm{IG}$ that indicates the effective substitution of $\mathrm{Ca}$ in the garnet lattice [21].

After probing the evolution of the structural properties of the doped BIG films upon annealing and doping at the macroscopic scale, the as-grown and TA96 $\mathrm{B}\left(\mathrm{Ca}_{0.0} \mathrm{Y}_{0.5}\right) \mathrm{IG}$ and as-grown $\mathrm{B}\left(\mathrm{Ca}_{0.3} \mathrm{Y}_{0.2}\right) \mathrm{IG}$ films were selected to investigate their local structural and chemical characteristics by 

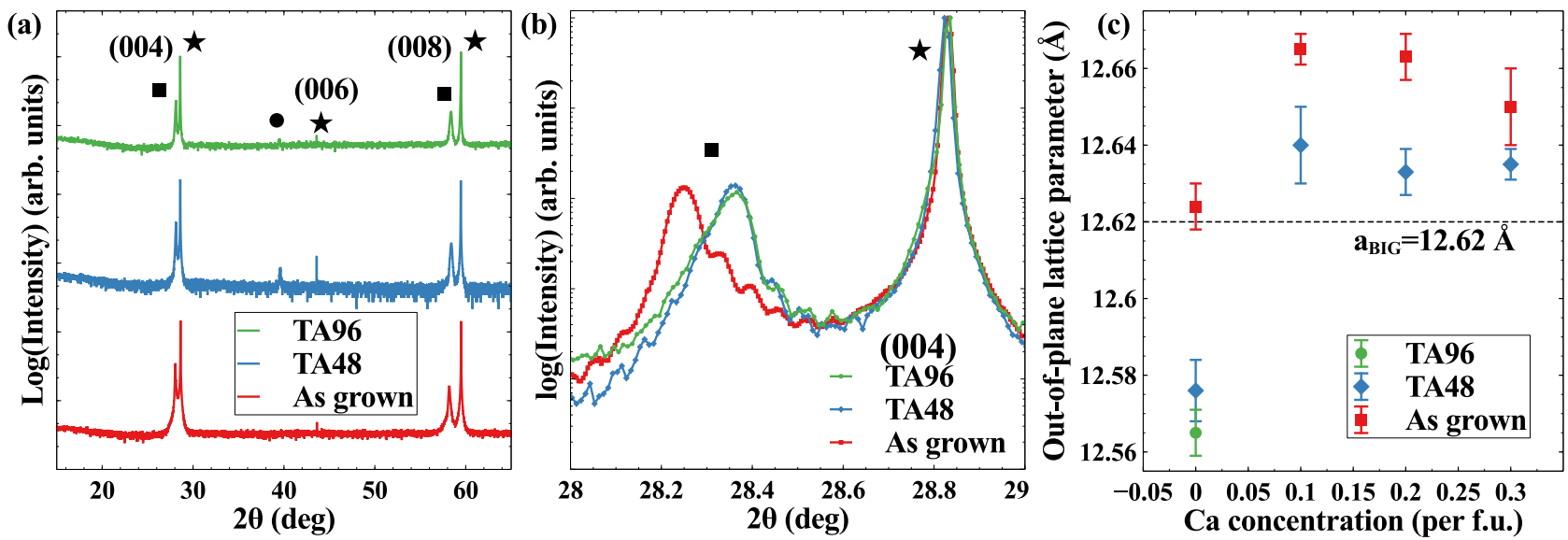

FIG. 1. (a) $\theta-2 \theta$ XRD scans of $\mathrm{B}\left(\mathrm{Ca}_{0.0} \mathrm{Y}_{0.5}\right) \mathrm{IG}$ before and after TA48 and TA96. The peaks corresponding to $\mathrm{B}\left(\mathrm{Ca} \mathrm{a}_{0.0} \mathrm{Y}_{0.5}\right) \mathrm{IG}$, GGG and Pt contact pads are highlighted by a square, a star and a circle, respectively. (b) Zoom of a) on the (004) reflection. (c) Evolution of out-of-plane lattice parameter with the nominal Ca concentration for as-grown, TA48 and TA96 thin films.

electron spectro-microsocopy. Figure 2(a) shows a typical low magnification TEM bright-field image of the as-grown $\mathrm{B}\left(\mathrm{Ca}_{0.0} \mathrm{Y}_{0.5}\right) \mathrm{IG}$. The selected area electron diffraction pattern in Fig. 2(b) confirms the high structural quality of the film. A typical STEM bright-field image displayed in Fig. 2(c) shows, at higher magnification, that $\mathrm{B}\left(\mathrm{Ca}_{0.0} \mathrm{Y}_{0.5}\right) \mathrm{IG}$ exhibits columnar growth, with column widths of $\approx 40 \mathrm{~nm}$ that can also be distinguished in Fig. 2(a). Secondary phase nanoneedles are observed mostly in between garnet grains and one of them is highlighted by two white arrowheads in Fig. 2(c). Their widths varies from 5 to $30 \mathrm{~nm}$. They start to form at about 20 $\mathrm{nm}$ above the film/substrate interface and reach the surface of the film. The nanocrystallites are still present after TA96 and were observed in all doped BIG films that were investigated using electron microscopy.

The chemical and electronic natures of the nanoneedles were further locally probed by STEM-EELS to determine which phase these nanocrystallites belong to. The $\mathrm{O} K$ and Fe $L_{2,3}$ absorption edges of the secondary phase inclusions are compared with those of pure BIG films and of a hematite $\left(\alpha-\mathrm{Fe}_{2} \mathrm{O}_{3}\right)$ reference in Fig. 3(a). The $\mathrm{O} K$ edge of $\alpha-\mathrm{Fe}_{2} \mathrm{O}_{3}$ consists of the $\mathrm{A} 1$ peak at $530 \mathrm{eV}$ and of the B peak at $540 \mathrm{eV}$
[22]. A1 corresponds to the hybridization of $\mathrm{O} 2 p$ states with $\mathrm{Fe} 3 d$ states while $\mathrm{B}$ is assigned to the hybridization of $\mathrm{O} 2 p$ states with $\mathrm{Fe} 4 s$ and $4 p$ states [23]. In BIG, the $\mathrm{O} K$ edge has an additional peak at $533 \mathrm{eV}$ labeled A2 that corresponds notably to the hybridization of $\mathrm{O} 2 p$ states with Bi $6 p$ states [24]. The $\mathrm{O} K$ edge of nanoneedles does not possess the A2 peak and the $\mathrm{B}$ peak is more intense than the A1 peak, similar to $\alpha-\mathrm{Fe}_{2} \mathrm{O}_{3}$. The $\mathrm{Bi} M_{4,5}$ edge was also probed (not shown here) in the nanocrystallites and exhibited a large intensity decay. A part of the garnet phase is always probed by EELS along with the nanoneedles as their diameters are thinner than the thickness of the FIB lamella $(\approx 70 \mathrm{~nm})$. Thus a residual intensity of the $\mathrm{Bi} M_{4,5}$ edge is observed in the nanocrystallites. The absence of the A2 peak, together with the lower $\mathrm{Bi} M_{4,5}$ intensity indicate a strong Bi depletion in the nanocrystallites. Besides, the Fe $L_{2,3}$ edges of pure BIG, nanocrystallite and $\alpha-\mathrm{Fe}_{2} \mathrm{O}_{3}$ [Fig. 3(a) right panel] show the typical fine structures of $\mathrm{Fe}^{3+}$ [25]. These results strongly indicate that the nanocrystallites are mainly composed of a binary ferric oxide.

A typical STEM-HAADF image with atomic-scale resolution is presented in Fig. 3(b) at the boundary between the
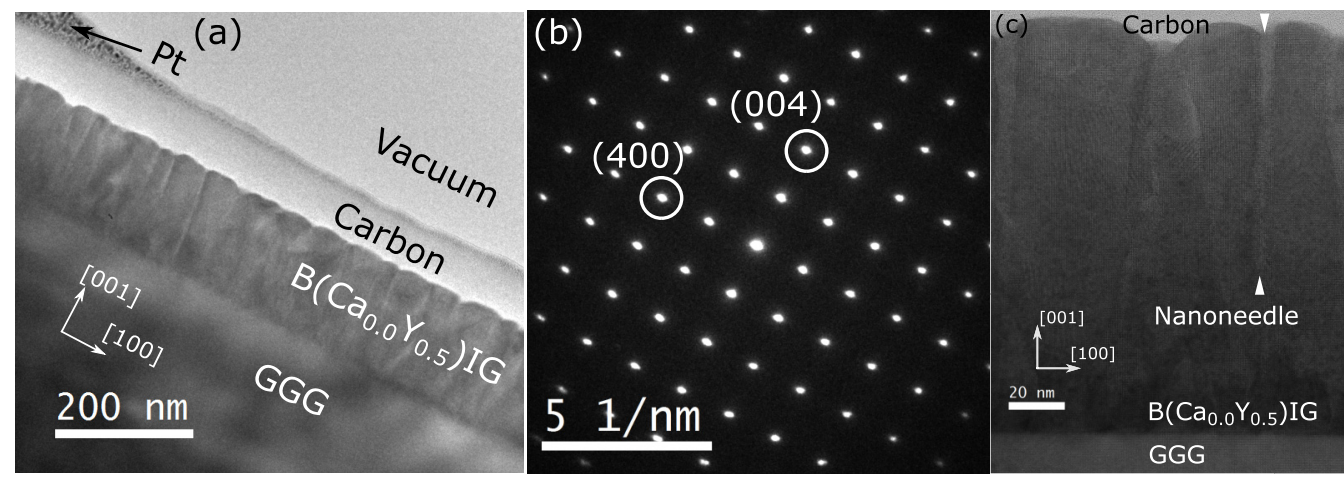

FIG. 2. (a) TEM bright-field low-magnification image of as-grown $\mathrm{B}\left(\mathrm{Ca}_{0.0} \mathrm{Y}_{0.5}\right) \mathrm{IG}$. (b) Diffraction pattern of a selected area in the film shown in (a). The (004) and (400) reflections are highlighted by white circles. (c) STEM bright-field image of as-grown $\mathrm{B}\left(\mathrm{Ca} \mathrm{a}_{0.0} \mathrm{Y}_{0.5}\right) \mathrm{IG}$. The presence of a nanocrystallite is highlighted by two white arrowheads. 

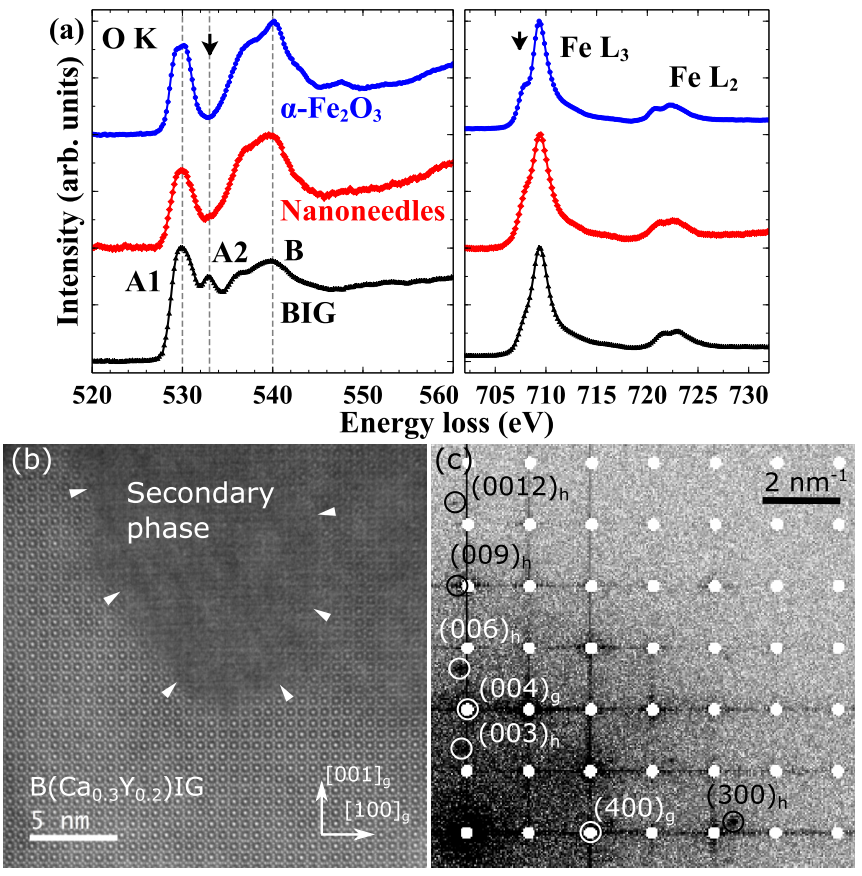

FIG. 3. (a) Sum of $\mathrm{O} K$ and Fe $L$ edges spectra acquired in $\alpha-\mathrm{Fe}_{2} \mathrm{O}_{3}$, nanocrystallites and BIG in blue, red and black, respectively. The nanocrystallite spectrum is the sum of 1500 spectra of 30 $\mathrm{ms}$ each with a dispersion of $0.18 \mathrm{eV} \mathrm{ch}^{-1}$. The two other spectra are the sum of 10 times more spectra acquired the same way. (b) HAADF image of as-grown $\mathrm{B}\left(\mathrm{Ca}_{0.3} \mathrm{Y}_{0.2}\right) \mathrm{IG}$ and a part of nanocrystallite highlighted by white arrowheads. (c) Fourier transform modulus of (b) with inverse grayscale contrasts. The reflections from the nanocrystallite are noted $(\mathrm{mnp})_{\mathrm{h}}$ and those of the garnet are noted $(\mathrm{mnp})_{\mathrm{g}}$. The interplanar distance of hematite $(009)_{\mathrm{h}}=0.159 \mathrm{~nm}$ almost coincides with the $(008)_{\mathrm{g}}=0.158 \mathrm{~nm}$ of garnet film.

garnet and the secondary phases. A typical nanocrystallite appears as a low intensity area marked by white arrowheads in line with the observed $\mathrm{Bi}$ depletion. Atomic planes of the nanocrystallite are visible but they often appear with a faint contrast or show a structural disorder. It indicates that the ferric iron oxide is rather weakly crystallized and this feature could explain the absence of $\alpha-\mathrm{Fe}_{2} \mathrm{O}_{3}$ peaks in the XRD patterns. In Fig. 3(b), the fast Fourier transform (FFT) of Fig. 3(a) exhibits the reflections of the garnet lattice (with a $g$ subscript) and additional reflections (with a $h$ subscript) from the nanocrystallite. In Fig. 3(c), the reflections of the nanocrystallites correspond to a hematite $(R \overline{3} c)$ observed along the $[010]_{\mathrm{h}}$ zone axis (hexagonal system). These results, correlated with those obtained by EELS, indicate that the secondary phase has the same structure as that of the $\alpha-\mathrm{Fe}_{2} \mathrm{O}_{3}$. As shown in Fig. 3(c), the hematite $(009)_{\mathrm{h}}$ planes (interplanar distance of $0.159 \mathrm{~nm}$ ) almost coincide with the garnet $(008)_{\mathrm{g}}$ planes (interplanar distance of $0.158 \mathrm{~nm}$ ) resulting in an interfacial relationship as observed in Fig. 3(b). More generally, it is observed that the $[001]_{\mathrm{h}}$ axis of many observed nanocrystallites makes an angle ranging roughly from $2^{\circ}$ to $25^{\circ}$ with the $[001]_{\mathrm{g}}$ axis of the garnet phase as derived from the FFTs of STEM-HAADF images. The secondary phase is then made of poorly crystallized hematite nanocrystallites with a textured orientation with respect to the garnet grains. It is interesting to note that the presence of these nanocrystallites is not detected by conventional macroscopic techniques such as XRD. This underlines the importance of transmission electron spectromicroscopy studies to provide a local and detailed chemical and crystallographic analysis of such microstructural features of materials. The latter assertion is especially true in the case of Bi-rich thin films that do not exist as bulk and which space group is not yet fully known.

While pure BIG thin films, less than $100 \mathrm{~nm}$ thick, can be grown by PLD under similar conditions to those of the $(\mathrm{Ca}, \mathrm{Y}): \mathrm{BIG}[4]$, the occurrence of secondary phase inclusions was already reported in pure BIG in other research groups. These inclusions are most often composed of $\mathrm{BiFeO}_{3}[14,26]$ and $\mathrm{Bi}_{2} \mathrm{Fe}_{4} \mathrm{O}_{9}$ [27]. Their formation occurs at high $\left(\mathrm{PO}_{2}>\right.$ $17 \mathrm{~Pa})$ or low $\left(\mathrm{PO}_{2}<0.1 \mathrm{~Pa}\right)$ oxygen partial pressure during the growth and they are usually detected directly by XRD. The only example of secondary phase inclusions not detectable by XRD was reported by Kahl et al. [15] in BIG grown by PLD on GGG but the structural and chemical natures of these inclusions were not identified.

More generally, secondary phase inclusions are often observed in bismuth iron oxides. A classic example of such wellstudied oxide is $\mathrm{BiFeO}_{3}$ (BFO). As for BIG, the PLD growth of $\mathrm{BFO}$ still remains a complex topic and is only possible in a narrow range of partial oxygen pressures. For $\mathrm{PO}_{2}$ below $\approx 0.7 \mathrm{~Pa}$, inclusions of $\alpha-\mathrm{Fe}_{2} \mathrm{O}_{3}$, maghemite $\left(\gamma-\mathrm{Fe}_{2} \mathrm{O}_{3}\right)$ or more scarcely magnetite $\left(\mathrm{Fe}_{3} \mathrm{O}_{4}\right)$ form while for $\mathrm{PO}_{2}$ above ca. 2.7 $\mathrm{Pa}$ the formation of $\mathrm{Bi}_{2} \mathrm{O}_{3}$ occurs [28-30]. These effects originate mainly from the high volatility of $\mathrm{Bi}$ ions [29] and it is likely that the same mechanism is present in the growth of BIG. In some cases, these secondary phase inclusions can be nanometric in size and may remain undetectable by conventional macroscopic techniques such as XRD [31]. In the case of BFO, the addition of dopants change the PLD growth conditions necessary to obtain single-phase thin films [31-33]. By comparison with the growth characteristics of $\mathrm{BFO}$, it can thus be concluded that the unexpected formation of $\alpha-\mathrm{Fe}_{2} \mathrm{O}_{3}$ in $\mathrm{B}\left(\mathrm{Ca}_{x} \mathrm{Y}_{0.5-x}\right) \mathrm{IG}$ thin films originate from an insufficient oxidation during growth.

GPA were performed to determine the local lattice parameter variations in the garnet phase, in both $i-p$ and o-o-p directions, especially at the film/substrate interface. A typical STEM-HAADF image of as-grown $\mathrm{B}\left(\mathrm{Ca}_{0.0} \mathrm{Y}_{0.5}\right) \mathrm{IG}$ used for the GPA is shown in Fig. 4(a). The extracted i-p and o-o-p relative strain maps of the film are displayed in Figs. 4(b) and 4(c), respectively. Extracted profiles from both the o-o-p and i-p strain maps of as-grown and TA96 $\mathrm{B}\left(\mathrm{Ca}_{0.0} \mathrm{Y}_{0.5}\right) \mathrm{IG}$ are displayed in Figs. 4(d) and 4(e), respectively. For both TA96 and as-grown films, the strain relaxation mechanisms are similar. The compressive strain of about $2 \%$ induced by the substrate is fully relaxed on $\approx 20 \mathrm{~nm}$ from the film/substrate interface by in-plane pseudo-periodic dislocations. This strain relaxation mechanism is analogous to that of BIG on substitutedGGG [4]. For the as-grown film, the relaxed lattice parameters are $1.269 \mathrm{~nm}$ i-p and $1.261 \mathrm{~nm}$ o-o-p. The i-p strain is relaxed over a length of $15 \mathrm{~nm}$ i-p by approximately one dislocation every $18 \mathrm{~nm}$. For the TA96 film, the relaxed lattice parameters are $1.263 \mathrm{~nm}$ i-p and $1.268 \mathrm{~nm}$ o-o-p. The i-p strain is relaxed over a length of $21 \mathrm{~nm}$ i-p by approximately one dislocation 

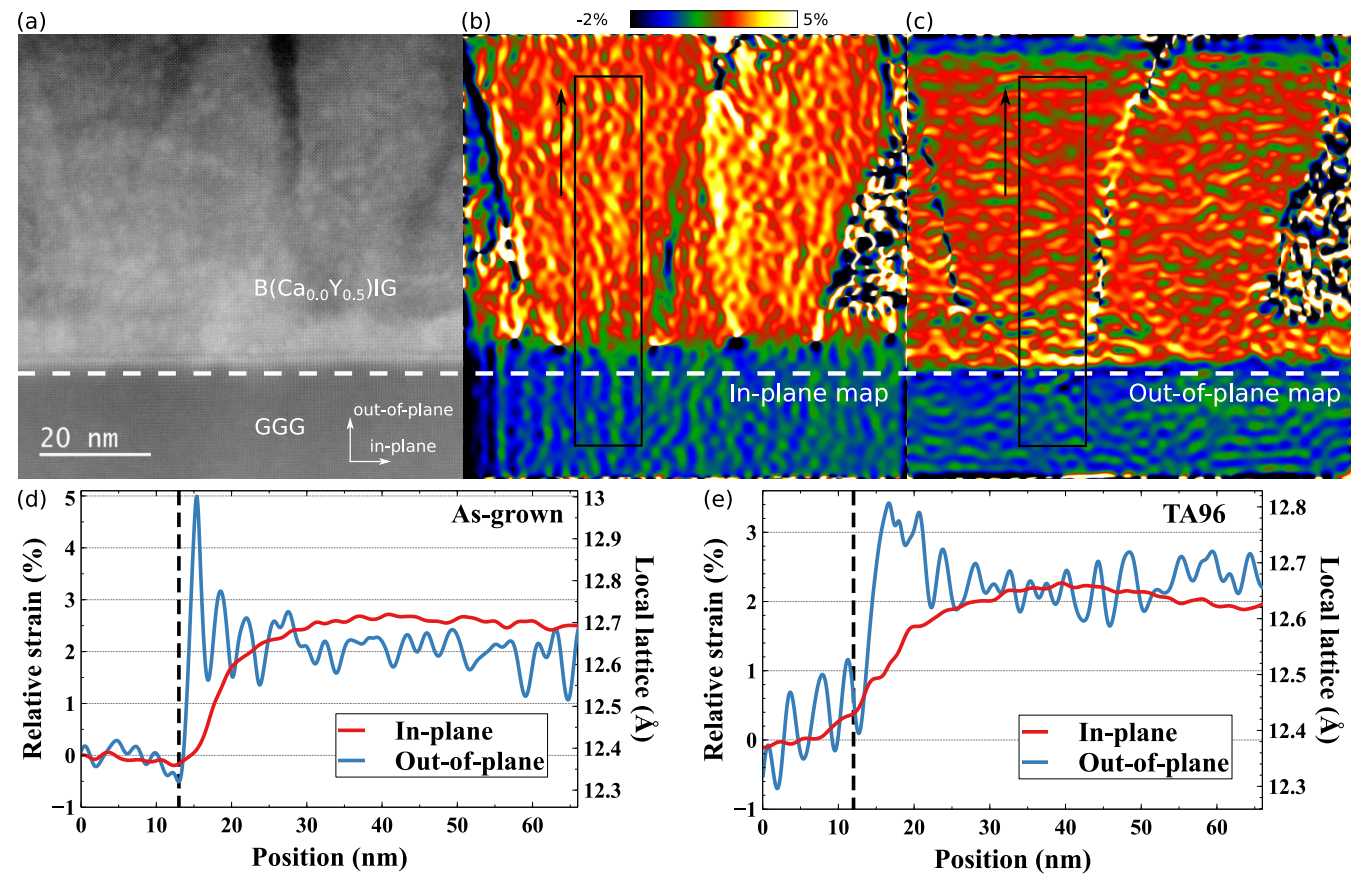

FIG. 4. (a) High-resolution HAADF image of the film substrate/interface for as-grown $B\left(\mathrm{Ca}_{0.0} \mathrm{Y}_{0.5}\right) \mathrm{IG}$. Extracted in-plane (b) and out-ofplane (c) relative strain maps from GPA on a) where the substrate is taken as reference. (d) Extracted profiles from the i-p and o-o-p relative strain maps of (b) and (c), respectively. The black boxes in (b) and (c) indicate the profile extraction regions. (e) Extracted profiles for TA96 $\mathrm{B}\left(\mathrm{Ca}_{0.0} \mathrm{Y}_{0.5}\right) \mathrm{IG}$ from the i-p and o-o-p relative strain maps derived from GPA. The black dashed line indicates the position of the film/substrate interface.

every $27 \mathrm{~nm}$. These results are consistent with those obtained by XRD where a lower strain is expected in TA96 $\mathrm{B}\left(\mathrm{Ca}_{0.0} \mathrm{Y}_{0.5}\right) \mathrm{IG}$. For both TA96 and as-grown films, the o-o-p lattice parameter is fully relaxed right from the film/substrate interface contrary to the i-p lattice parameter. This difference of relaxation lengths induces locally a tetragonal deformation of the unit cell in the strained region with a o-o-p/i-p lattice parameters ratio of up to $2 \%$ for both as-grown and TA96 films. In the relaxed region the unit cell of the films remains cubic supporting the assumption that the unit cell volume can be derived from the o-o-p lattice parameter. The films are structurally homogeneous over almost their whole thickness and the annealing tends to decrease the density of misfit dislocations. The presence of a textured secondary phase in the upper part of the film does not play a role in the relaxation of the film.

In the following, the results obtained by Faraday spectroscopy and Kerr rotation are discussed, particularly in relation to the structural and microstructural properties presented above. The Faraday rotation spectra between 1.5 and $4 \mathrm{eV}$ were acquired for as-grown and TA48 $\mathrm{B}\left(\mathrm{Ca}_{x} \mathrm{Y}_{0.5-x}\right) \mathrm{IG}$ as shown in Figs. 5(a) and 5(b), respectively. All the spectra of the substituted garnets show overall spectral shapes and intensities similar to the Faraday rotation spectrum of BIG despite the presence of the secondary phase inclusions in the doped films. Except for $\mathrm{B}\left(\mathrm{Ca}_{0.3} \mathrm{Y}_{0.2}\right) \mathrm{IG}$, an increase of the Faraday rotation intensity between $8 \%$ to $14 \%$ is observed upon annealing for the substituted thin films. The effect of this post-annealing could not be verified for pure $\mathrm{BIG}$, since the garnet phase in undoped film is not stable under TA48 $(870 \mathrm{~K})$ but at least the $\theta_{F}$ does not evolve upon annealing for 48 hours at $625 \mathrm{~K}$ under an $\mathrm{O}_{2}$ flux of 50 $\mathrm{ml} \mathrm{min}{ }^{-1}$. In addition, a blue shift is also observed for $\mathrm{Ca}$ and Y co-substituted BIG MO spectra.

In BIG, the Faraday rotation (intensity, fine structures) is driven by magneto-optical transitions from the ground state to the excited states mainly corresponding to the different $\mathrm{Fe}$ sublattices. There are three cation sublattices in the garnet structure. The $\mathrm{Bi}$ sites are surrounded by eight $\mathrm{O}$ anions forming a dodecahedral $\left(T_{\mathrm{h}}\right)$ cage while the Fe sites are surrounded by either four or six $\mathrm{O}$ anions forming tetrahedral $\left(T_{\mathrm{d}}\right)$ or octahedral cages $\left(\mathrm{O}^{h}\right)$, respectively. Charge-transfer transitions from filled states with a strong $\mathrm{O} 2 p$ character to $\mathrm{Fe} 3 d$ empty states are believed to be responsible for the MO effects in the visible range in iron garnets [34,35]. These states are both split by a strong exchange interaction and the Fe $3 d$ states are further split by the spin-orbit coupling. The Bi $6 p$ states are hybridized with empty and filled Fe $3 d$ states and with filled O $2 p$ states [34-37]. This hybridization leads to a strong increase of the spin-orbit coupling for both $\mathrm{O} 2 p$ and $\mathrm{Fe} 3 d$ states that yields an enhancement of the Faraday effect.

To be more quantitative the commonly accepted model to explain the MO spectrum of BIG was applied. This model is based on two magneto-optical transitions (so-called diamagnetic) from a degenerate filled state to Fe empty states split by the exchange interaction and the effective spin-orbit induced by hybridization with $\mathrm{Bi} 6 p$ empty states [9]. A diamagnetic transition is parametrized by a transition energy (E), an energy splitting $(\Delta)$, a line-width $(\Gamma)$ and the product (Nf) of the 

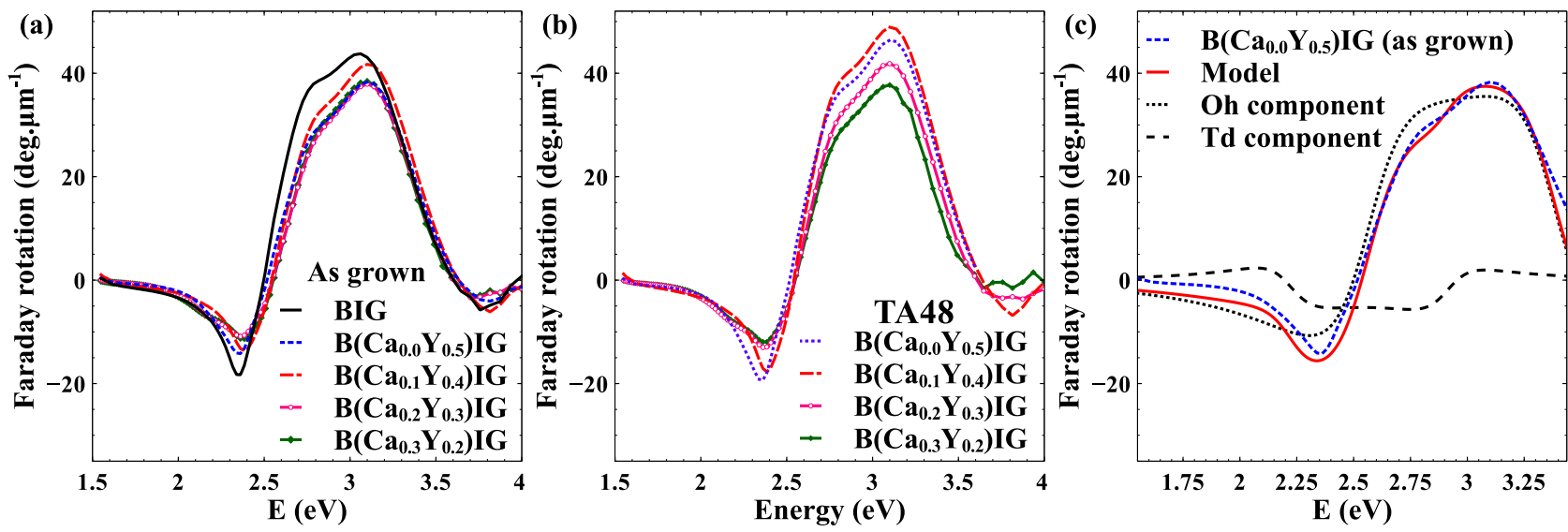

FIG. 5. (a) Faraday rotation spectra for as grown thin films. (b) Faraday rotation spectra for TA48 thin films. (c) Experimental Faraday rotation spectrum of $\mathrm{B}\left(\mathrm{Ca}_{0.0} \mathrm{Y}_{0.3}\right) \mathrm{IG}$ (blue dashed line) with its corresponding theoretical model (red line). The black dotted and dashed lines correspond to the octahedral and tetrahedral components of the theoretical model, respectively.

number of active centers $(\mathrm{N})$ and oscillator strength (f). $\Gamma$ and $\Delta$ drive the shape and the intensity of the transition while $\mathrm{Nf}$ is only linked to its intensity. The transitions at around $E_{\mathrm{Oh}}=3.0 \mathrm{eV}$ and $E_{\mathrm{Td}}=2.5 \mathrm{eV}$ are associated with the $\mathrm{Fe}$ $\mathrm{Oh}$ and Fe Td sublattices, respectively [9,38]. A typical fit result is presented in Fig. 5(c) and the extracted parameters (Nf and E) are shown in Table I. One should note that the least-square fitting of $\mathrm{Td}$ transition yields noisier results due to its lower intensity, therefore the main interpretation is based on the Oh transition parameters in the following. A blue shift of $\Delta E_{t} \mathrm{Oh}=60 \mathrm{meV}$ with respect to BIG is observed for $\mathrm{B}\left(\mathrm{Ca}_{0.0} \mathrm{Y}_{0.5}\right) \mathrm{IG}$ while for $\mathrm{Ca}$ containing films a shift of $\Delta E_{\mathrm{Oh}}=80 \mathrm{meV}$ is determined. Significant changes in $\mathrm{Nf}$ are also obtained after annealing and are discussed below especially concerning the $\mathrm{Oh}$ transition.

A blue shift of the MO transitions was observed in $\mathrm{Y}_{3-x} \mathrm{Bi}_{x} \mathrm{Fe}_{5} \mathrm{O}_{12}$ thin films with decreasing $\mathrm{Bi}$ content [16]. This feature can be explained by the band gap increase from BIG (2.3 eV [39]) to YIG (3.0 eV [40]). The blue shift of MO spectra for Ca and Y co-substituted BIG confirms the lower concentration of $\mathrm{Bi}$ with respect to pure $\mathrm{BIG}$ [9]. The transition intensity $\mathrm{Nf}$ of as-grown films is lower than the one of BIG as this quantity scales with the Bi concentration. However, for TA48 films $\mathrm{Nf}_{\mathrm{Oh}}$ increases and it can be clearly seen in Fig. 5(b) that the Faraday rotation even reaches higher values for $\mathrm{B}\left(\mathrm{Ca}_{0.1} \mathrm{Y}_{0.4}\right) \mathrm{IG}$ and $\mathrm{B}\left(\mathrm{Ca}_{0.0} \mathrm{Y}_{0.5}\right) \mathrm{IG}$ than that of pure BIG. These high $\mathrm{Nf}_{\mathrm{Oh}}$ values can be related to the decrease of the unit cell volume upon annealing which increases the hybridization between the $\mathrm{Bi}$, $\mathrm{O}$ and $\mathrm{Fe}$ electronic states. As-grown thin films might also present $\mathrm{Fe}^{2+}$ due to oxygen off-stoichiometry [5]. This could reduce the magneto-optical effects while in TA48 films all Fe should tend to $3+$ valence yielding an enhanced Faraday rotation.

Its high $T_{\mathrm{C}}$ is an important asset of the BIG especially for ambient temperature applications and was therefore systematically probed in the doped BIG. The variations of $T_{\mathrm{C}}$ for the $\mathrm{B}\left(\mathrm{Ca}_{x} \mathrm{Y}_{0.5-x}\right) \mathrm{IG}$ series are displayed in Fig. 6(a) as a function of the nominal stoichiometry and in Fig. 6(b) as a function of the o-o-p lattice parameter. The $\mathrm{B}\left(\mathrm{Ca}_{x} \mathrm{Y}_{0.5-x}\right) \mathrm{IG}$ films have $T_{\mathrm{C}}$ between 602 to $658 \mathrm{~K}$. This behavior is expected since the $T_{\mathrm{C}}$ of the parent phases ranges from $560 \mathrm{~K}$ for YIG to $660 \mathrm{~K}$ for BIG with a monotonous change within $\mathrm{Y}_{3-x} \mathrm{Bi}_{x} \mathrm{Fe}_{5} \mathrm{O}_{12}$ thin films [16]. The volume of the unit cell is expected to have the strongest influence on the $T_{\mathrm{C}}$. When the unit cell volume decreases, the $\mathrm{O} 2 p$ and $\mathrm{Fe} 3 d$ orbitals are more overlapped and the superexchange interaction is therefore enhanced resulting in a direct increase of the $T_{\mathrm{C}}$. Besides, the evolution of the Fe-O-Fe bonding angles also influences the superexchange interaction [41]. In particular,

TABLE I. Transition energies and Nf values of the Oh and Td components of the fitted theoretical model before and after TA48 for all thin films. The transitions energies and Nf values of BIG are also displayed for comparison.

\begin{tabular}{|c|c|c|c|c|c|c|c|c|}
\hline & \multicolumn{4}{|c|}{ As-grown } & \multicolumn{4}{|c|}{ TA48 } \\
\hline & \multicolumn{2}{|c|}{$\mathrm{Nf}\left(10^{17} \mathrm{~cm}^{-3}\right)$} & \multicolumn{2}{|c|}{ Energy (eV) } & \multicolumn{2}{|c|}{$\mathrm{Nf}\left(10^{17} \mathrm{~cm}^{-3}\right)$} & \multicolumn{2}{|c|}{ Energy $(\mathrm{eV})$} \\
\hline & $\mathrm{Oh}$ & $\mathrm{Td}$ & $\mathrm{Oh}$ & $\mathrm{Td}$ & $\mathrm{Oh}$ & $\mathrm{Td}$ & $\mathrm{Oh}$ & $\mathrm{Td}$ \\
\hline BIG & 3.89 & 1.11 & 2.91 & 2.47 & & & & \\
\hline $\mathrm{B}\left(\mathrm{Ca}_{0.0} \mathrm{Y}_{0.5}\right) \mathrm{IG}$ & 3.47 & 0.38 & 2.97 & 2.57 & 4.04 & 0.72 & 2.96 & 2.52 \\
\hline $\mathrm{B}\left(\mathrm{Ca}_{0.1} \mathrm{Y}_{0.4}\right) \mathrm{IG}$ & 3.67 & 0.25 & 2.99 & 2.61 & 4.25 & 0.31 & 2.99 & 2.61 \\
\hline $\mathrm{B}\left(\mathrm{Ca}_{0.2} \mathrm{Y}_{0.3}\right) \mathrm{IG}$ & 3.57 & 0.21 & 2.99 & 2.56 & 3.98 & 0.33 & 2.98 & 2.55 \\
\hline $\mathrm{B}\left(\mathrm{Ca}_{0.3} \mathrm{Y}_{0.2}\right) \mathrm{IG}$ & 3.75 & 0.34 & 2.99 & 2.63 & 4.25 & 0.60 & 2.96 & 2.57 \\
\hline
\end{tabular}



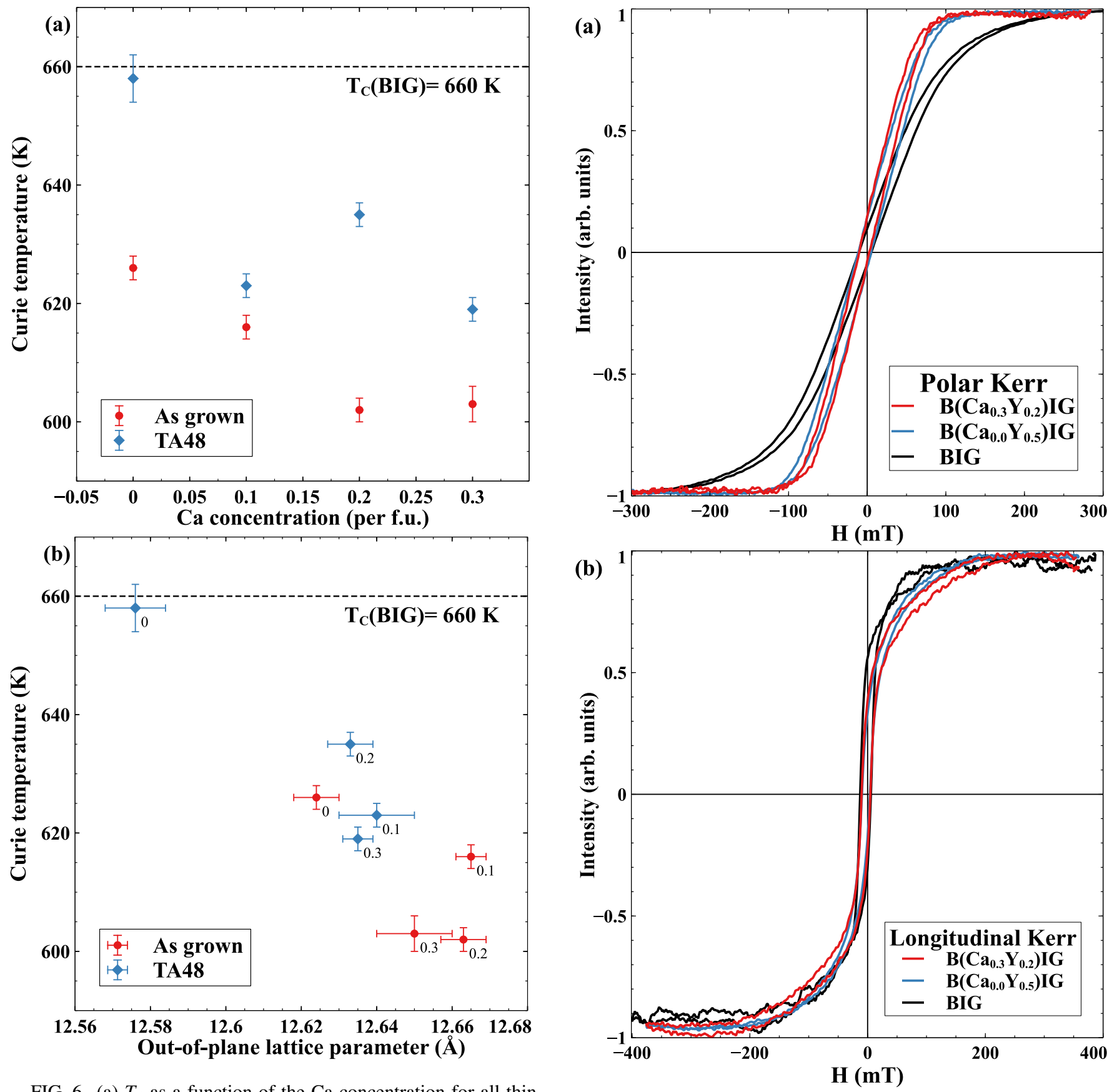

FIG. 6. (a) $T_{\mathrm{C}}$ as a function of the Ca concentration for all thin films before and after TA48. (b) $T_{\mathrm{C}}$ as a function of the o-o-p lattice parameter for all thin films before and after TA48. The corresponding $\mathrm{Ca}$ concentration is indicated at the bottom right of every point. The $T_{\mathrm{C}}$ of BIG is indicated by a dashed line for comparison.

these angles may change with the lattice parameters and might have an additional effect on the $T_{\mathrm{C}}$. These results confirm that the magnetism in $\mathrm{B}\left(\mathrm{Ca}_{x} \mathrm{Y}_{0.5-x}\right) \mathrm{IG}$ remains robust despite the $\mathrm{Ca}$ and $\mathrm{Y}$ co-substitution, the presence of minor secondary phase inclusions and, in the case of as-grown thin films, the oxygen off-stoichiometry.

The Kerr rotation was also measured to obtain a better understanding of the magnetic properties and identify a possible effect of the presence of the nanoneedles. For $\mathrm{B}\left(\mathrm{Ca}_{0.0} \mathrm{Y}_{0.5}\right) \mathrm{IG}$, $\mathrm{B}\left(\mathrm{Ca}_{0.3} \mathrm{Y}_{0.2}\right) \mathrm{IG}$ and $\mathrm{BIG}$, the longitudinal (i-p direction)

FIG. 7. (a) Kerr hysteresis cycles of BIG, $\mathrm{B}\left(\mathrm{Ca}_{0.0} \mathrm{Y}_{0.5}\right) \mathrm{IG}$ and $\mathrm{B}\left(\mathrm{Ca}_{0.3} \mathrm{Y}_{0.2}\right) \mathrm{IG}$ in polar (o-o-p) configuration. (b) Kerr hysteresis cycles of $\mathrm{BIG}, \mathrm{B}\left(\mathrm{Ca}_{0.0} \mathrm{Y}_{0.5}\right) \mathrm{IG}$ and $\mathrm{B}\left(\mathrm{Ca}_{0.3} \mathrm{Y}_{0.2}\right) \mathrm{IG}$ in longitudinal (i-p) configuration.

and polar (o-o-p direction) M-O Kerr effect were measured [Figs. 7(a) and 7(b), respectively]. The o-o-p saturation field ranges from $130 \mathrm{mT}$ for $\mathrm{B}\left(\mathrm{Ca}_{0.3} \mathrm{Y}_{0.2}\right) \mathrm{IG}$ to more than $300 \mathrm{mT}$ for BIG. The i-p saturation field varies from $120 \mathrm{mT}$ for BIG to $230 \mathrm{mT}$ for $\mathrm{B}\left(\mathrm{Ca}_{0.3} \mathrm{Y}_{0.2}\right) \mathrm{IG}$. For a few hundreds of nanometers thick thin films of $\mathrm{BIG}$, its easy magnetization axis is parallel to the i-p direction [26,42]. However, for $\mathrm{Ca}$ and $\mathrm{Y}$ co-substituted BIG films, the easy magnetization axis changes from i-p to o-o-p. Considering the saturation magnetization of $10^{5} \mathrm{~A} \mathrm{~m}^{-1}$ for this film, its perpendicular anisotropy can be 
roughly estimated to be $\frac{M_{s} H_{s}}{2}=7 \times 10^{4} \mathrm{~J} \mathrm{~m}^{-3}$. To understand the origin of this phenomenon, different contributions in the magnetic anisotropy compete and should be considered. First, the substrate-induced strain should be taken in account. For all films, the GGG substrate applies a compressive strain. This strain is at the origin of a negative magnetoelastic anisotropy that tends to put the observed magnetization in the film plane [8] and is therefore not responsible for the change in anisotropy. Similarly, the shape anisotropy is negative for a thin film and is not responsible for the o-o-p anisotropy. Another possibility resides in a change of the growth anisotropy upon doping as evidenced in Bi-substituted YIG [8]. The garnet thin films have nonequivalent dodecahedral sites due to the preferential direction induced by epitaxial growth [43]. A Bi population difference between these nonequivalent sites can yield the growth anisotropy that tends to rotate the easy magnetization axis in the o-o-p direction $[44,45]$. However, in BIG, all the dodecahedral sites are filled and the magnetization stays in-plane. Hence, in Ca and Y co-substituted BIG, a growth anisotropy might also contribute to the change of easy magnetization axis despite the absence of evidence to support this explanation in the present work. Assuming that the presence of nanoneedles at the grain boundaries limits the typical size of the magnetic domains to that of a garnet grain, the dipolar coupling between the grains may also induce the observed change in anisotropy [46]. It is also known that a columnar microstructure of magnetic thin films significantly enhances their perpendicular anisotropy [47]. Finally, an additional anisotropy could arise due to the presence of the oriented nanocrystallites. The hematite nanocrystallites are textured antiferromagnets and their interaction with the main ferrimagnetic garnet phase could yield an exchange anisotropy [48-50]. To probe a possible exchange bias due to the presence the weakly crystallized secondary phase, classical field cooling experiments were performed in two configurations. On the one hand, Faraday rotation measurements were done after cooling from 700 to $300 \mathrm{~K}$ with an applied magnetic field perpendicular to the film plane. On the other hand, vibrating sample magnetometer was used to measure hysteresis curves after field cooling from 300 to $10 \mathrm{~K}$ in an magnetic field applied parallel to the film plane. In either configuration, no unambiguous exchange bias signature was detected.

\section{CONCLUSION}

Thin conducting films of $\mathrm{Bi}_{2.5} \mathrm{Ca}_{x} \mathrm{Y}_{0.5-x} \mathrm{Fe}_{5} \mathrm{O}_{12}(x=0.0$; $0.1 ; 0.2 ; 0.3)$ were grown on GGG (001) substrates as potential candidates for magnetic semiconductors at room temperature [5]. Detailed macroscopic and microscopic structural properties, strain relaxation, magneto-optical and magnetic properties of these doped $\mathrm{B}\left(\mathrm{Ca}_{x} \mathrm{Y}_{0.5-x}\right) \mathrm{IG}$ films were investigated before and after thermal annealing under oxidizing conditions as a function of dopant concentration. The films show high structural quality evidenced by XRD with cubeon-cube epitaxial growth. Post-growth annealing in oxidizing atmosphere allowed the filling of the oxygen lattice while preserving structural properties of the films and decreasing the density of dislocations. Accordingly, a decrease of $0.1 \%$ to $0.3 \%$ of the o-o-p lattice parameter was observed upon annealing. Faraday rotation spectroscopy in the visible range reveals similar spectral signature to that of BIG. The Faraday rotation intensity increased upon annealing and reached up to $12 \%$ above that of undoped BIG over the studied spectral range $(1.5$ to $4 \mathrm{eV})$. The magnetic ordering remained robust upon doping and annealing with $T_{\mathrm{C}}$ of up to $660 \mathrm{~K}$. As expected, the Curie temperature increased after annealing. The easy magnetization axis of the thin films goes from i-p to o-o-p as a possible effect of either the $\mathrm{Ca}$ and $\mathrm{Y}$ substitution on $\mathrm{Bi}$ site or the columnar microstructure of the thin films. The presence of a minor secondary phase between perfectly crystallized garnet grains was evidenced solely by (S)TEM while it was not detectable by XRD. After a detailed study by Cs-STEM/EELS, this secondary phase is identified as weakly crystallized and weakly textured $\alpha-\mathrm{Fe}_{2} \mathrm{O}_{3}$ nanoneedles. Oxygen-deficient atmosphere during the growth could be at the origin of the appearance of these nanoneedles. Despite the presence of the nanoneedles all the films exhibit state-ofthe-art magnetic and magneto-optical properties.

\section{ACKNOWLEDGMENTS}

The authors acknowledge Ecole Doctorale Physique en Ile-de-France (EDPIF) for the PhD grant of Adrien Teurtrie. The authors acknowledge funding from the French National Research Agency under the program of future investment TEMPOS (No. ANR-10-EQPX-0050) for the FIB access.
[1] L. Martin, Y.-H. Chu, and R. Ramesh, Advances in the growth and characterization of magnetic, ferroelectric, and multiferroic oxide thin films, Mater. Sci. Eng., R 68, 89 (2010).

[2] M. Deb, E. Popova, A. Fouchet, and N. Keller, Full spin polarization of complex ferrimagnetic bismuth iron garnet probed by magneto-optical faraday spectroscopy, Phys. Rev. B 87, 224408 (2013).

[3] E. Popova, A. Shengelaya, D. Daraselia, D. Japaridze, S. Cherifi-Hertel, L. Bocher, A. Gloter, O. Stéphan, Y. Dumont, and N. Keller, Bismuth iron garnet $\mathrm{Bi}_{3} \mathrm{Fe}_{5} \mathrm{O}_{12}$ : A room temperature magnetoelectric material, Appl. Phys. Lett. 110, 142404 (2017).

[4] E. Popova, M. Deb, L. Bocher, A. Gloter, O. Stéphan, B. Warot-Fonrose, B. Berini, Y. Dumont, and N. Keller, In- terplay between epitaxial strain and low dimensionality effects in a ferrimagnetic oxide, J. Appl. Phys. 121, 115304 (2017).

[5] A. Teurtrie, E. Popova, I. Koita, E. Chikoidze, N. Keller, A. Gloter, and L. Bocher, Atmosphere-induced reversible resistivity changes in $\mathrm{Ca} / \mathrm{Y}$-doped bismuth iron garnet thin films, Adv. Funct. Mater. 29, 1904958 (2019).

[6] J. L. MacManus-Driscoll, Self-assembled heteroepitaxial oxide nanocomposite thin film structures: Designing interfaceinduced functionality in electronic materials, Adv. Funct. Mater. 20, 2035 (2010).

[7] Z. Liao, M. Huijben, Z. Zhong, N. Gauquelin, S. Macke, R. J. Green, S. Van Aert, J. Verbeeck, G. Van Tendeloo, K. Held, G. A. Sawatzky, G. Koster, and G. Rijnders, Controlled 
lateral anisotropy in correlated manganite heterostructures by interface-engineered oxygen octahedral coupling, Nat. Mater. 15, 425 (2016).

[8] L. Soumah, N. Beaulieu, L. Qassym, C. Carrétéro, E. Jacquet, R. Lebourgeois, J. Ben Youssef, P. Bortolotti, V. Cros, and A. Anane, Ultra-low damping insulating magnetic thin films get perpendicular, Nat. Commun. 9, 3355 (2018).

[9] M. Deb, E. Popova, A. Fouchet, and N. Keller, Magnetooptical Faraday spectroscopy of completely bismuth-substituted $\mathrm{Bi}_{3} \mathrm{Fe}_{5} \mathrm{O}_{12}$ garnet thin films, J. Phys. D: Appl. Phys. 45, 455001 (2012).

[10] J. Ferré, Linear and non-linear magneto-optical effects: magnetism of thin films, in Magnetism and Synchrotron Radiation, edited by E. Beaurepaire, F. Scheurer, F. Krill, and J.-P. Kappler, Lecture Notes in Physics, Vol. 565 (Springer, Berlin, Heidelberg, 2001), pp. 316-355.

[11] C. Koch, FRWRtools plugin, https://www.physics.hu-berlin.de/ en/sem/software/software_frwrtools (2019-07-17).

[12] Y. Zhu, C. Ophus, J. Ciston, and H. Wang, Interface lattice displacement measurement to $1 \mathrm{pm}$ by geometric phase analysis on aberration-corrected HAADF STEM images, Acta Mater. 61, 5646 (2013).

[13] P. Johansson, S. Khartsev, and A. Grishin, Comparison of $\mathrm{Bi}_{3} \mathrm{Fe}_{5} \mathrm{O}_{12}$ film giant faraday rotators grown on (111) and (001) $\mathrm{Gd}_{3} \mathrm{Ga}_{5} \mathrm{O}_{12}$ single crystals, Thin Solid Films 515, 477 (2006).

[14] B. Vertruyen, R. Cloots, J. S. Abell, T. J. Jackson, R. C. da Silva, E. Popova, and N. Keller, Curie temperature, exchange integrals, and magneto-optical properties in off-stoichiometric bismuth iron garnet epitaxial films, Phys. Rev. B 78, 094429 (2008).

[15] S. Kahl, S. I. Khartsev, A. M. Grishin, K. Kawano, G. Kong, R. A. Chakalov, and J. S. Abell, Structure, microstructure, and magneto-optical properties of laser deposited $\mathrm{Bi}_{3} \mathrm{Fe}_{5} \mathrm{O}_{12} / \mathrm{Gd}_{3} \mathrm{Ga}_{5} \mathrm{O}_{12}$ (111) films, J. Appl. Phys. 91, 9556 (2002).

[16] M.-Y. Chern, F.-Y. Lo, D.-R. Liu, K. Yang, and J.-S. Liaw, Red shift of faraday rotation in thin films of completely bismuthsubstituted iron garnet $\mathrm{Bi}_{3} \mathrm{Fe}_{5} \mathrm{O}_{12}$, Jpn. J. Appl. Phys. 38, 6687 (1999).

[17] S. Kahl and A. Grishin, Evolution of properties of epitaxial bismuth iron garnet films with increasing thickness, J. Magn. Magn. Mater. 278, 244 (2004).

[18] R. D. Shannon, Revised effective ionic radii and systematic studies of interatomic distances in halides and chalcogenides, Acta Crystallogr., Sect. A A32, 751 (1976).

[19] M.-Y. Chern and J.-S. Liaw, Study of $\mathrm{Bi}_{x} \mathrm{Y}_{3-x} \mathrm{Fe}_{5} \mathrm{O}_{12}$ thin films grown by pulsed laser deposition, Jpn. J. Appl. Phys. 36, 1049 (1997).

[20] E. Popova, N. Keller, F. Gendron, M. Guyot, M.-C. Brianso, Y. Dumond, and M. Tessier, Structure and magnetic properties of yttrium-iron-garnet thin films prepared by laser deposition, J. Appl. Phys. 90, 1422 (2001).

[21] Y. Wang, L. Zhang, Y. Fan, J. Luo, D. E. McCready, C. Wang, and L. An, Synthesis, characterization, and optical properties of pristine and doped yttrium aluminum garnet nanopowders, J. Am. Ceram. Soc. 88, 284 (2005).

[22] C. Colliex, T. Manoubi, and C. Ortiz, Electron-energy-lossspectroscopy near-edge fine structures in the iron-oxygen system, Phys. Rev. B 44, 11402 (1991).
[23] F. M. F. de Groot, M. Grioni, J. C. Fuggle, J. Ghijsen, G. A. Sawatzky, and H. Petersen, Oxygen 1s x-ray-absorption edges of transition-metal oxides, Phys. Rev. B 40, 5715 (1989).

[24] R. Sæterli, S. M. Selbach, P. Ravindran, T. Grande, and R. Holmestad, Electronic structure of multiferroic $\mathrm{BiFeO}_{3}$ and related compounds: Electron energy loss spectroscopy and density functional study, Phys. Rev. B 82, 064102 (2010).

[25] P. S. Miedema and F. M. de Groot, The iron 1 edges: Fe 2p x-ray absorption and electron energy loss spectroscopy, J. Electron. Spectrosc. Relat. Phenom. 187, 32 (2013).

[26] N. Adachi, V. P. Denysenkov, S. I. Khartsev, A. M. Grishin, and T. Okuda, Epitaxial $\mathrm{Bi}_{3} \mathrm{Fe}_{5} \mathrm{O}_{12}$ (001) films grown by pulsed laser deposition and reactive ion beam sputtering techniques, $\mathrm{J}$. Appl. Phys. 88, 2734 (2000).

[27] E. Popova, L. Magdenko, H. Niedoba, M. Deb, B. Dagens, B. Berini, M. Vanwolleghem, C. Vilar, F. Gendron, A. Fouchet, J. Scola, Y. Dumont, M. Guyot, and N. Keller, Magnetic properties of the magnetophotonic crystal based on bismuth iron garnet, J. Appl. Phys. 112, 093910 (2012).

[28] H. Béa, M. Bibes, S. Fusil, K. Bouzehouane, E. Jacquet, K. Rode, P. Bencok, and A. Barthélémy, Investigation on the origin of the magnetic moment of $\mathrm{BiFeO}_{3}$ thin films by advanced $\mathrm{x}$-ray characterizations, Phys. Rev. B 74, 020101(R) (2006).

[29] M. Murakami, S. Fujino, S.-H. Lim, L. G. Salamanca-Riba, M Wuttig, I. Takeuchi, B. Varughese, H. Sugaya, T. Hasegawa, and S. E. Lofland, Microstructure and phase control in bi-fe-o multiferroic nanocomposite thin films, Appl. Phys. Lett. 88, 112505 (2006).

[30] X. Wang, Y. Zhu, S. Mi, C. Wang, H. Lu, and X. Ma, Morphology and orientation of iron oxide precipitates in epitaxial $\mathrm{BiFeO}_{3}$ thin films grown under two non-optimized oxygen pressures, Philos. Mag. 90, 4551 (2010).

[31] H. Zhang, I. M. Reaney, D. M. Marincel, S. Trolier-McKinstry, Q. M. Ramasse, I. MacLaren, S. D. Findlay, R. D. Fraleigh, I. M. Ross, S. Hu, W. Ren, and W. Mark Rainforth, Stabilisation of $\mathrm{Fe}_{2} \mathrm{O}_{3}$-rich perovskite nanophase in epitaxial rare-earth doped BiFeO3 films, Sci. Rep. 5, 13066 (2015).

[32] Y. Sharma, R. Martinez, R. Agarwal, D. Barrionuevo, R. K. Katiyar, A. Kumar, and R. S. Katiyar, Studies on structural, optical, magnetic, and resistive switching properties of doped $\mathrm{BiFe}_{1-x} \mathrm{Cr}_{x} \mathrm{O}_{3}$ thin films, J. Appl. Phys. 120, 194101 (2016).

[33] A. Gaur, P. Singh, N. Choudhary, D. Kumar, M. Shariq, K Singh, N. Kaur, and D. Kaur, Structural, optical and magnetic properties of $\mathrm{Nd}$-doped $\mathrm{BiFeO}_{3}$ thin films prepared by pulsed laser deposition, Physica B: Condens. Matter 406, 1877 (2011).

[34] S. Wittekoek, T. J. A. Popma, J. M. Robertson, and P. F. Bongers, Magneto-optic spectra and the dielectric tensor elements of bismuth-substituted iron garnets at photon energies between 2.2-5.2 eV, Phys. Rev. B 12, 2777 (1975).

[35] K. Shinagawa, Faraday and Kerr effects in ferromagnets, in Magneto-Optics, edited by S. Sugano and N. Kojima (Springer, Berlin, Heidelberg, 2000), pp. 137-177.

[36] T. Oikawa, S. Suzuki, and K. Nakao, First-principles study of spinorbit interactions in bismuth iron garnet, J. Phys. Soc. Jpn. 74, 401 (2005).

[37] F. Iori, A. Teurtrie, L. Bocher, E. Popova, N. Keller, O. Stéphan, and A. Gloter, Bismut iron garnet: Ab initio study of electronic properties, Phys. Rev. B 100, 245150 (2019). 
[38] G. F. Dionne and G. A. Allen, Spectral origins of giant faraday rotation and ellipticity in bisubstituted magnetic garnets, J. Appl. Phys. 73, 6127 (1993).

[39] S. Kahl, V. Popov, and A. M. Grishin, Optical transmission and faraday rotation spectra of a bismuth iron garnet film, J. Appl. Phys. 94, 5688 (2003).

[40] R. Vidyasagar, O. Alves Santos, J. Holanda, R. O. Cunha, F. L. A. Machado, P. R. T. Ribeiro, A. R. Rodrigues, J. B. S. Mendes, A. Azevedo, and S. M. Rezende, Giant zeeman shifts in the optical transitions of yttrium iron garnet thin films, Appl. Phys. Lett. 109, 122402 (2016).

[41] W. Noun, E. Popova, F. Bardelli, Y. Dumont, R. Bertacco, A. Tagliaferri, M. Tessier, M. Guyot, B. Berini, and N. Keller, Determination of yttrium iron garnet superexchange parameters as a function of oxygen and cation stoichiometry, Phys. Rev. B 81, 054411 (2010).

[42] E. Popova, A. F. Franco Galeano, M. Deb, B. WarotFonrose, H. Kachkachi, F. Gendron, F. Ott, B. Berini, and N. Keller, Magnetic anisotropies in ultrathin bismuth iron garnet films, J. Magn. Magn. Mater. 335, 139 (2013).

[43] P. Novák, Contribution of $\mathrm{Fe}^{3+}$ ions to the growth induced anisotropy in garnet films, Czech. J. Phys. 34, 1060 (1984).
[44] V. J. Fratello, S. E. G. Slusky, C. D. Brandle, and M. P. Norelli, Growthinduced anisotropy in bismuth: Rareearth iron garnets, J. Appl. Phys. 60, 2488 (1986).

[45] P. Hansen, C.-P. Klages, J. Schuldt, and K. Witter, Magnetic and magneto-optical properties of bismuth-substituted lutetium iron garnet films, Phys. Rev. B 31, 5858 (1985).

[46] P. Mendoza Zélis, V. Vega, V. M. Prida, L. C. Costa-Arzuza, F. Béron, K. R. Pirota, R. López-Ruiz, and F. H. Sánchez, Effective demagnetizing tensors in arrays of magnetic nanopillars, Phys. Rev. B 96, 174427 (2017).

[47] J. Dubowik, Shape anisotropy of magnetic heterostructures, Phys. Rev. B 54, 1088 (1996).

[48] A. E. Berkowitz and K. Takano, Exchange anisotropy - a review, J. Magn. Magn. Mater. 200, 552 (1999).

[49] W. Zhang, L. Li, P. Lu, M. Fan, Q. Su, F. Khatkhatay, A. Chen, Q. Jia, X. Zhang, J. L. MacManus-Driscoll, and H. Wang, Perpendicular exchange-biased magnetotransport at the vertical heterointerfaces in $\mathrm{La}_{0.7} \mathrm{Sr}_{0.3} \mathrm{MnO}_{3}: \mathrm{NiO}$ nanocomposites, ACS Appl. Mater. Interfaces 7, 21646 (2015).

[50] W. Zhang, A. Chen, J. Jian, Y. Zhu, L. Chen, P. Lu, Q. Jia, J. L. MacManus-Driscoll, X. Zhang, and H. Wang, Strong perpendicular exchange bias in epitaxial $\mathrm{La}_{0.7} \mathrm{Sr}_{0.3} \mathrm{MnO}_{3}: \mathrm{BiFeO}_{3}$ nanocomposite films through vertical interfacial coupling, Nanoscale 7, 13808 (2015). 